\title{
SWIMMERS: A RECAPITULATION of the Problem and a Potential Solution
}

\author{
By David M. Karl and George A. Knauer
}

A finite but variable

percent of the biogenic

materials collected by

sediment traps may

partition into the solute

phase.
$\mathrm{W}$ 't al. (1988) concerning the effects of "swimmers" on the measurement of particulate organic matter flux in the marine environment. Generally swimmers are either: (1) acknowledged and their impact reduced by manually removing the carcasses ("picking") before further sample processing, (2) acknowledged, but trap contents analyzed unaltered, or (3) totally ignored. None of these three options is acceptable, if the desired outcome is to obtain accurate particle flux estimates. As Lee et al. (1988) discuss in their review, the swimmer problem is exacerbated in near-surface waters $(\leq 500 \mathrm{~m})$. Unfortunately, the measurement of particulate organic matter flux in the upper water column is crucial to our understanding of biogenic element cycles, including the rates and mechanisms of nutrient regeneration and, consequently, crucial to addressing the Global Ocean Flux Study (GOFS) program objectives (Brewer of al., 1986). Because sediment traps are now recognized as the only method for estimating the passive downward flux of organic matter in the sea (SCOR WG-71 report on "Particulate Biogeochemical Processes," S. Krishnaswami. chairman), our progress toward a resolution of these important oceanic processes is stalled at this time. So, to provide a brief answer to the rhetorical question posed in their title, "Are 'Swimmers" a Problem?," we believe the reply is an overwhelming affirmative.

In fact, the problem of swimmers may be more severe than stated in the Lee et al. (1988) review. To date, most measurements of sediment trap-collected materials have focused on the particulate phase. However, it is well known that a finite but variable percent of the biogenic materials collected by sediment traps may partition into the solute phase (Knauer et al., 1979; Knauer et al.. 1984). The extent to which the particulate constituents disaggregate/disintegrate, dissolve, hydrolyse or remineralize after entering the sediment trap will depend upon a number of complex variables that are not understood at the present time. If one ignores the solute phase during sample processing, one will certainly underestimate the true

David M. Karl, Department of Oceanography and Hawaii Institute of Geophysics, University of Hawaii. Honolulu. HI 96822; and Georgc A. Knauer, Center for Marine Science. University of Southem Mississippi, Stennis Space Center, MS 39529. passive downward flux of biogenic matter in the sea. If swimmers are present, the solute phase will be contaminated by materials that have been leached from the carcasses. Removal of the swimmers by "picking" the sample does not address the swimmerderived solute contamination problem, which for elements like $\mathrm{C}$. N and $\mathrm{P}$ may be substantial. Furthermore, if preservatives/poisons are used (e.g., formalin, glutaraldehyde, azide, mercuric chloride, etc.) the problem becomes insurmountable, either becausc of the overwhelming $C$ (e.g. formalin and glutaraldehyde) or $\mathrm{N}$ (azide) contributed by the preservative, or because of an accelerated disintegration of the organic matter when a poison (e.g.. azide, mercuric chloride) rather than a preservative is employed. Several of these issues were discussed recently at a U.S. GOFS-sponsored workshop at the University of Southern Mississippi's Center for Marine Science. A report summarizing the majority opinions should be available from the U.S. GOFS Planning Office in spring 1989 (H. Livingston, Woods Hole, Massachusetts 02543). Even though the data presented by Lee et al. (1988) and the results presented in this paper were obtained using VERTEXstyle traps that are deployed and recovered in an open configuration for periods of $\geq 6 \mathrm{~d}$, the problem of swimmers is common to all sediment trap experiments regardless of collection time, trap configuration or water column depth. It is fair to state that there is now an overwhelming consensus that actively swimming macro- and microzooplankton inadvertently collected in all moored and free-drifting sediment traps are a major obstacle to further progress in oceanic flux investigations.

At the conclusion of their review article, Lee $\mathrm{et} \mathrm{al}$. (1988) indicated that "few rigorous studies of the effect of swimmers on trap-derived fluxes have been carried out." The authors go on to suggest that, as a community, we might either try to determine the impact of swimmers and take corrective actions or, as a better solution to this ubiquitous problem, design a trap system that would eliminate the problem. The GOFS workshop participants concluded that a "unique solution" to the swimmer problem is not in sight. In fact, there was little agreement on even a general methodological approach, except for the fact that swimmers must be removed before further process- 


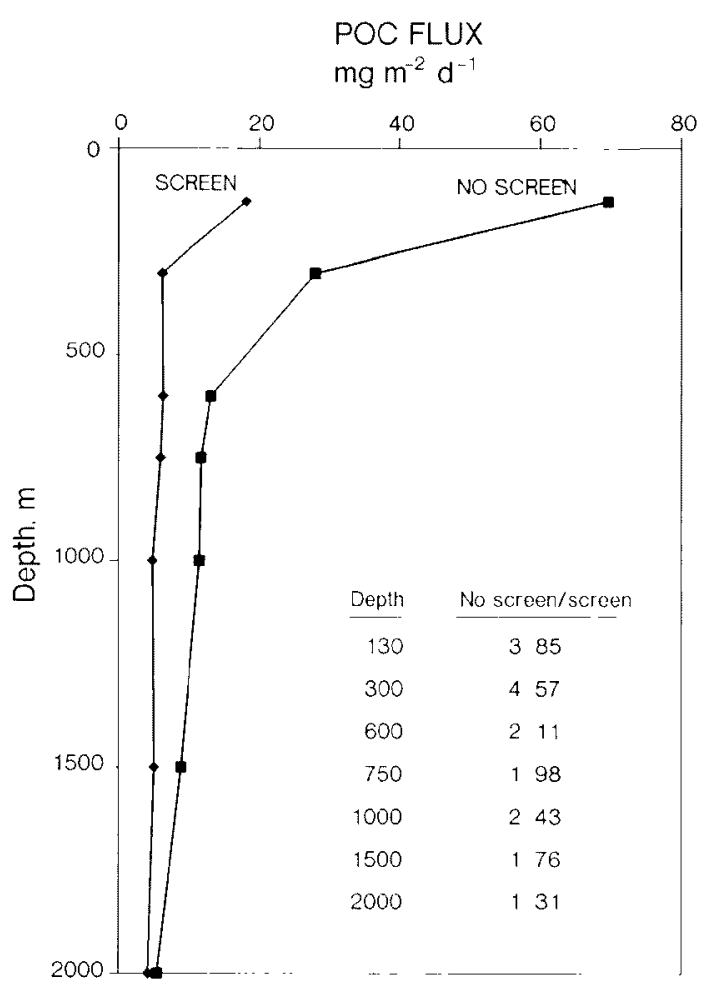

Fig. 1: Particulate organic carbon (POC) fluxmeasured using traps with and without $335 \mu \mathrm{m}$ screens at a station located in the North Pacific Ocean $\left(35^{\circ} \mathrm{N}\right.$. $\left.128^{\circ} \mathrm{W}\right)$. The POCfluxes measuredfor the "no screen" traps were measured after the removal of swimmers and the POC fluxes measured for the "screen" traps were made without further sample processing. The table in the lower right corner of the figure presents the value of $Y / Z$ (i.e., ratio of no screen/screen $P O C$ flux; see text for details) for each sample depth.

ing of sediment trap-collected materials. As the GOFS program moves forward with funded sediment trap experiments in the North Pacific and North Atlantic Oceans, it behooves us to concentrate on at least a first-order method of correcting our current particle flux determinations for the presence of swimmers. Below we propose one analytical solution and discuss its potential field application and limitations.

Our current recommendation is based on the re- sults of field experiments that were conducted as part of the NSF-sponsored VERTEX program. Early attempts to repel macrozooplankton by the presence of noxious chemicals were uniformly unsuccessful, as were our attempts to gain an in situ separation of the passive and active flux through the use of Nitex ${ }^{R}$ screens. The potential solution which we now present relies on the deployment of at least two (and preferably more) sediment traps at each depth. The Multitrap system (Knauer et al., 1979), or a trap array of similar design, is recommended because of the ability to deploy up to 14 replicate collectors per depth. One trap (or set of traps, if replication is possible) is configured with a $335 \mu \mathrm{m}$ Nitex $^{R}$ screen at the base of the baffle and contains no added poison or preservative. A hypersaline solution, prepared by dissolving $40 \mathrm{~g}$ reagent grade $\mathrm{NaCl}$ per liter of filtered seawater, is used in these traps to prevent advective-diffusive loss of the accumulated solutes and to eliminate flushing of the traps during recovery. $\mathrm{NaCl}$ is used to increase the density of the seawater rather than the "3-salt mix" (Karl and Knauer, 1984), because of its desirable inhibitory effect on microbial activity. Since the presence of a high density solution will affect the aspect ratio of the sediment trap (1988 GOFS-sponsored Sediment Trap Workshop Proceedings), it is imperative to control the brine level so as to maintain a minimum aspect ratio of 5 throughout the deployment period. It is our intent with this treatment to reduce the in situ microbiological processes to a minimum during the trap deployment period without the addition of a preservative or posion that might otherwise interfere with the measurement of dissolved $\mathrm{C}, \mathrm{N}$ or $\mathrm{P}$. This treatment is subsequently referred to as the unpreserved-screened trap. The second trap (or set of traps) is deployed without a screen and with a high density seawater- $\mathrm{NaCl}$ solution (as above), but also containing $1 \%$ formalin (final concentration). This treatment is subsequently referred to as the preservedunscreened trap.

Following recovery of the traps, the preservedunscreened samples are examined under a dissecting microscope and those organisms identified as swimmers are removed from the trap material (Knauer $e t$ al., 1979, 1984; Knauer and Martin, 1981). The remaining particulate matter is analyzed for $\mathrm{C}, \mathrm{N}, \mathrm{P}$,
The potential

solution which we

now present relies

on the deployment of

at least two ...

sediment traps

at each depth. 
$\mathrm{Si}$, etc. The unpreserved-screened traps are likewise processed for particulate $\mathrm{C}, \mathrm{N}, \mathrm{P}, \mathrm{Si}$, etc. and the solute portions $(0.2 \mu \mathrm{m}$ filtrate, or equivalent $)$ are also analyzed for total dissolved C, N, P, Si, etc. by appropriate, standard methodologies with dilutions to reduce the salt effect, as required.

We estimate the total trap C (or N, P, Si, etc.), with the following equation:

Total $=\mathrm{X}(\mathrm{Y} / \mathrm{Z}) \quad$ Eq. 1

where:

$$
\text { Total }=\mathrm{X}(\mathrm{Y} / \mathrm{Z})
$$

$\mathrm{X}=$ total particulate plus dissolved $\mathrm{C}$ in the unpreserved-screened trap

$\mathrm{Y}=$ total particulate $\mathrm{C}$ (swimmer-corrected) in the preserved-unscreened trap

$\mathrm{Z}=$ total particulate $\mathrm{C}$ in the unpreserved-screened trap.

The assumptions inherent in this approach are: (1) individual traps deployed at the same depth can be treated as replicate collections, (2) $335 \mu \mathrm{m}$ mesh screens eliminate contamination by actively-swimming macrozooplankton, (3) microbial decomposition of the particulate materials does not occur in the unpreserved trap samples. and (4) sample integrity and percent solubilization of the collected particulate matter does not vary between the preserved and unpreserved treatments.

The first assumption has. been evaluated previously under field conditions (Knauer et al., 1984). In two separate experiments conducted in coastal waters with the collection periods of 6 and $20.6 \mathrm{~d}$, the reproducibility among sediment traps deployed at the same depth was found to be excellent (coefficient of variation $\leq 8 \%$ ). With regard to the effectiveness of the $335 \mu \mathrm{m}$ screens, we recommend that the in situ screened sediment trap sample be examined microscopically to evaluate this assumption. If swimmer contamination persists for a given habitat, a smaller

\begin{tabular}{|c|c|c|c|}
\hline \multirow{2}{*}{$\begin{array}{c}\begin{array}{c}\text { Screen } \\
\text { Treatment }\end{array} \\
\text { none }\end{array}$} & \multicolumn{2}{|c|}{${ }_{\left(m g m^{-2} \mathrm{~d}^{-1}\right)}^{\text {N Flux }}{ }^{\text {Flux }}$} & \multirow[t]{2}{*}{$\begin{array}{l}\mathrm{C}: \mathrm{N} \\
(\mathrm{wt})\end{array}$} \\
\hline & $\begin{array}{l}23.5 \\
21.5\end{array}$ & $\begin{array}{l}4.32 \\
4.05\end{array}$ & \\
\hline & $x=22.5(100 \%)^{+}$ & $4.19(100 \%)$ & 5.38 \\
\hline \multirow[t]{2}{*}{$2 \mathrm{~mm}$ Nitex } & $\begin{array}{l}16.3 \\
18.3\end{array}$ & $\begin{array}{l}2.75 \\
2.95\end{array}$ & \\
\hline & $x=\overline{17.3(77 \%)}$ & $2.85(68 \%)$ & 6.07 \\
\hline \multirow[t]{2}{*}{1 mm Nitex } & $\begin{array}{l}16.6 \\
17.4\end{array}$ & $\begin{array}{l}2.93 \\
2.97\end{array}$ & \\
\hline & $x=\overline{17.0(76 \%)}$ & $2.95(70 \%)$ & 5.76 \\
\hline \multirow[t]{2}{*}{$335 \mu \mathrm{m}$ Nitex } & $\begin{array}{l}7.71 \\
8.20\end{array}$ & $\begin{array}{l}1.37 \\
1.56\end{array}$ & \\
\hline & $x=7.96(35 \%)$ & $1.47(35 \%)$ & 5.43 \\
\hline
\end{tabular}

Table 1: Effects of in situ screening on the measurement of $C$ and $N$ flux at a station off Pt. Sur, CA. $\left(35^{\circ} 40^{\prime} \mathrm{N} ; 123^{\circ} 50^{\prime} \mathrm{W}\right)$. The replicate sediment traps, containing a mixture of seawater-NaCl-formalin, were deployed at $40 \mathrm{~m}$ for a period of $12 \mathrm{~d}$ during April 1985.

diameter mesh could be employed. It should be emphasized that an accurate estimation of total flux does not require a quantitative collection of all sinking particulate matter with the screened treatment; as indicated in the equation above, a correction is applied for any differences between the preservedunscreened, swimmer-picked particulate determination and the unpreserved-screened samples. However, it is important that the screening procedures do not interfere with the qualitative composition of the

\begin{tabular}{|c|c|c|c|c|c|c|}
\hline $\begin{array}{l}\text { Trap } \\
\text { Depth } \\
(\mathrm{m})\end{array}$ & \multicolumn{3}{|c|}{$\begin{array}{l}\text { unpreserved-screened } \\
\text { treatment }\end{array}$} & $\begin{array}{l}\text { preserved- } \\
\text { unscreened } \\
\text { treatment } \\
\text { PON } \\
\text { ( } \mu \text { moles/trap) }\end{array}$ & $\begin{array}{c}\text { Total }^{*} \\
\text { Corrected } \\
N \\
\text { ( } \mu \text { moles/trap) }\end{array}$ & $\begin{array}{c}\text { Total } N \\
\text { Flux } \\
\left(\mu \text { moles } \mathrm{m}^{-2} \mathrm{~d}^{-1}\right)\end{array}$ \\
\hline 50 & 97.88 & 47.93 & 144.81 & 186.45 & 275.8 & 5,440 \\
\hline 100 & 29.36 & 16.43 & 45.79 & 143.65 & 224.5 & 4,428 \\
\hline 225 & 15.22 & 7.36 & 22.58 & 81.91 & 121.4 & 2,394 \\
\hline 475 & 4.11 & 7.77 & 11.88 & 26.98 & 78.2 & 1,542 \\
\hline 900 & 4.56 & 5.35 & 9.91 & 11.33 & 24.7 & 487 \\
\hline 1500 & 3.83 & 6.91 & 10.74 & 10.43 & 29.3 & 578 \\
\hline 2000 & 3.05 & 1.65 & 4.69 & 7.35 & 11.3 & 223 \\
\hline $\begin{array}{l}+\mathrm{DN} \text { a } \\
{ }^{*} \text { Using }\end{array}$ & $\begin{array}{l}\text { dissol } \\
\text { the te }\end{array}$ & $\mathrm{N}$ and & $N$, resp & & & \\
\hline
\end{tabular}

Table 2: Total $N$ flux estimation using the proposed Karl-Knauer swimmer correction procedures. Traps were deployed for $13 \mathrm{~d}$ at a station off central California $\left(35^{\circ} 40^{\prime} \mathrm{N}, 123^{\circ} 50^{\circ} \mathrm{W}\right)$ in June 1984. Total $(0-50 \mathrm{~m})$ rate of primary production during this period was estimated to be 95 mmoles $C \mathrm{~m}^{-2} d^{-1}$, or approximately 14.4 mmoles $N$ based on a Redfield ratio of $6.6(C: N)$. 
particulate materials collected. Ideally, one would like to minimize obstruction of passively sinking particles and maximize the exclusion of swimmers, in which case $Y / Z=1$ in Eq. 1 .

We have determined the qualitative and quantitative effects of screens in several independent field experiments (Fig. 1, p. 33, and Table 1, p. 34). As might be expected, the $(\mathrm{Y} / \mathrm{Z})$ ratio for particulate organic carbon (POC) varied with screen diameter (Table 1), ranging from $1.30(2 \mathrm{~mm})$ to $2.86(335$ $\mu \mathrm{m})$. We also observed a systematic depth-dependent variation for screens of constant mesh size (in this case, $335 \mu \mathrm{m}$; Fig. 1), suggesting a shift in the mean dimensions of the sinking particulate organic matter. In spite of an apparent exclusion of up to $70 \%$ of the total POC for selected screened samples, there does not appear to be any systematic change in the particulate $\mathrm{C}: \mathrm{N}$ ratios (Table 1). From these data, we conclude that the bulk chemical composition of the particulate matter collected in screened traps is probably not substantially different from the unscreened collections for the habitats investigated.

The final two assumptions have been evaluated indirectly during the course of several field experiments. The numerous direct comparisons of preserved and unpreserved sediment trap collections to date have failed to provide any evidence for in situ microbial decomposition in the absence of a preservative (Knauer et al., 1984; Williams, 1986; Noriki and Tsunogai, 1986; Karl et al., 1988: R. Peinert and C. Lee. personal communication). Knauer et al. (1984) conclude that "There were no significant differences in the $\mathrm{C}$ flux data regardless of whether preservatives were used...." and "...it is our opinion that decomposition was not significant over the short, six-day deployment for those traps deployed at 100 m." Based on the results of a series of field measurements, Karl et al. (1988) have also concluded that "large sinking particles are, in general, poor habitats for bacterial growth and therefore unlikely sites for active remineralization of organic matter." Apparently, from the results available to date, in situ microbial decomposition should not be a major concern in the application of our proposed swimmer correction procedure.

We have now had an opportunity to utilize the swimmer-influenced correction measures discussed above for the determination of total $\mathrm{N}$ flux in the marine environment (Table 2.p. 34). These data suggest that previously published $\mathrm{N}$ flux results may have been systematically underestimated by up to $50-100 \%$. If we compare our total $\mathrm{N}$ flux estimates to contemporaneous measurements of primary production we conclude that new production may exceed $30 \%$. Additional field studies, currently in progress at the Hawaii and Bermuda GOFS time-series sites. should provide further information on the relationships between euphotic zone production, food-web structure, and new production.

The procedure described herein is expected to be most reliable when applied to oceanic habitats where swimmers are dominated by large crustaceans and least reliable when jellies or other soft-bodied zooplankton are present. We also recommend the use of short-term deployments ( $\leq 7 \mathrm{~d}$ ) in order to minimize attraction of swimmers and in situ decomposition/hydrolysis of the collected particulate materials. Finally, we would like toemphasize that one person's artifact is another person's data. To the extent that swimmers represent a subset of the diel migrant zooplankton that might also contribute to net downward particle flux (Longhurst and Harrison, 1988), a careful study should be undertaken to incorporate these populations into a more comprehensive ecological model of the upper water column.

In summary, swimmers are truly the scourge of the sediment trap business, especially for the measurement of particle flux in the upper water column. We present our current swimmer correction procedures not as the final word but, hopefully, as a benchmark on the road to a better overall solution to this universal analytical problem. We fully expect and encourage debate and criticism, and we especially invite suggestions for improvement.

\section{Acknowledgements}

We thank C. Winn, G. Tien, D. Hebel and M. Tuel for their comments and contributions. This work was supported in part by National Science Foundation grants OCE82-16671. OCE8600462 and OCE88-00329. Contribution $\# 2098$ of the Hawaii Institute of Geophysics.

\section{References}

Brewer, P. G., K. W. Bruland, R. W. Eppley and J. J. McCarthy, 1986: The Global Ocean Flux Study (GOFS): Status of the U.S. GOFS program. EOS, 67, 827-832.

Karl, D. M. and G. A. Knauer, 1984: Vertical distribution, transport. and exchange of carbon in the northeast Pacific Ocean: evidence for multiple zones of biological activity. Deep-Sea Res., 31, 221-243. and John H. Martin, 1988: Downward flux of particulate organic matter in the ocean: a particle decomposition paradox. Nature, 332, 438-441.

Knauer, G. A., D. M. Karl, J. H. Martin and C. N. Hunter, 1984: In situ effects of selected preservatives on total carbon. nitrogen and metals collected in sediment traps. J. Mar Res. 42, 445-462.

and J. H. Martin, 1981: Primary production and carbonnitrogen fluxes in the upper $1.500 \mathrm{~m}$ of the northeast Pacific. Limnol. Oceanogr. 26, 181-186.

and K. W. Bruland, 1979: Fluxes of particulate carbon, nitrogen, and phosphorus in the upper water column of the northeast Pacific. Deep-Sea Res.. 26. 97-108

Lee. C.. S.G. Wakeham and J. I. Hedges, 1988: The measurement of oceanic particle flux - Are "swimmers" a problem? Oceanogr. Mag. 1(2). 34-36.

Longhurst, A. R. and W. G. Harrison, 1988: Vertical nitrogen flux from the oceanic photic zone by diel migrant zooplankton and nekton. Deep-Sea Res.. 35, 881-889.

Norkiki. S. and S. Tsunogai. 1986: Particulate fluxes and major components of settling particles from sediment trap experiments in the Pacific Ocean. Deep-Sea Res., 33. 903-912.

Williams, P. M.. 1986: Chemistry of the dissolved and particulate phases in the water column. Plankton Dynamics of the Southern Calffornia Bight, R. W. Eppley, Ed., SpringerVerlag. New York. 53-83. $\square$
Previously published

$\mathrm{N}$ flux results may have

been systematically

underestimated by up

to $50-100 \%$. 